\title{
A bibliometric analysis of rheumatology and COVID-19 researches
}

\author{
Ozge Pasin ${ }^{1}(1) \cdot$ Tugce Pasin ${ }^{2}(1)$
}

Received: 22 April 2021 / Revised: 11 June 2021 / Accepted: 23 June 2021 / Published online: 2 July 2021

(c) International League of Associations for Rheumatology (ILAR) 2021

\begin{abstract}
Objective COVID-19 has had a substantial impact on rheumatology. There were many studies about rheumatology and COVID-19. But there is no study about bibliometric analysis of these studies. This study provides a general overview of studies on rheumatology and COVID-19.

Methods Data were taken from the Web of Science (WoS) website. Analysis and network visualization mapping processes were carried out using VOSviewer. We used the following keywords: "COVID-19" and "Rheumatology"; "Coronavirus" and "Rheumatology"; "2019-nCoV" and "Rheumatology"; "SARS-CoV-2" and "Rheumatology"; "COVID-19" and "Rheumatic Disease"; "Coronavirus" and "Rheumatic Disease"; "2019-nCoV" and "Rheumatic Disease"; "SARS-CoV-2" and "Rheumatic Disease"; "COVID-19" and "Rheumatism"; "Coronavirus" and "Rheumatism"; "2019-nCoV" and "Rheumatism"; and "SARS-CoV-2" and "Rheumatism." A total of 234 publications were analyzed, and the correlations between citation numbers and reference counts, usage counts, and page numbers were analyzed with Spearman correlation coefficients.

Results The average number of citations per item was 6.03. The studies were cited 1411 times in total, and 1121 times without self-citations. The countries with the highest number of publications on rheumatology and COVID-19 were the USA and England; the countries with the highest number of citations were Italy and the USA, and Jinoos Yazdany was the most cited author. The Annals of the Rheumatic Diseases was the most cited journal, whereas the highest number of articles on rheumatology and COVID-19 were published in Arthritis and Rheumatology.

Conclusions Bibliometric analysis of rheumatology and COVID-19 can be useful to future studies because it provides a general perspective on the studies. This study provides an insight into the development of publications on rheumatology during the COVID-19 pandemic.
\end{abstract}

\section{Key Points}

- Covid-19 has substantial impact on rheumatology.

- There many studies about rheumatology and COVID-19. But there is no study about bibliometric analysis of these studies.

- This study provides a general perspective of the studies about rheumatology and COVID-19.

- This study aims to inform the efforts to improve the studies about rheumatology studies during the pandemic process and to analyze the publications about both rheumatology and COVID-19 with bibliometric methods.

- Bibliometric analysis about rheumatology and COVID-19 can be useful and helpful tool for future studies.

Keywords Analysis $\cdot$ Bibliometric $\cdot$ COVID-19 $\cdot$ Rheumatology

Ozge Pasin

ozgepasin90@yahoo.com.tr

1 Department of Biostatistics, Faculty of Medicine, Bezmialem Foundation University, Fatih, Istanbul, Turkey

2 Department of Physical Medicine and Rehabilitation, Istanbul Goztepe Training and Research Hospital, Istanbul, Turkey

\section{Introduction}

SARS-CoV-2 (severe acute respiratory coronavirus 2 syndrome), a new member of the coronavirus family, was first detected in Wuhan, China, in December 2019. The virus causes fever, cough, fatigue, loss of taste and smell, dyspnea, myalgia, vomiting, diarrhea, and progressive diseases. Severe forms can cause acute respiratory distress syndrome (ARDS) and death, with interstitial lung involvement accompanied by alveolar damage [1-3]. 
Patients with rheumatism are considered to be a COVID19-risk group. When patients with rheumatological diseases are diagnosed with a COVID-19 infection, they should immediately contact their rheumatologist. Rheumatologic diseases are heterogeneous. Corticosteroids, synthetic and biological disease-modifying antirheumatic drugs (DMARDs), increase the risk of disease aggravation because they cause immunosuppression [4]. It is essential to understand what is driving the increased risk of COVID-19-related deaths in rheumatologic patients during the pandemic. Hydroxychloroquine, used for the treatment of rheumatological diseases, was used in the prevention and treatment of COVID-19, but subsequent clinical trials have not found any benefit [5]. Cytokine inhibitor drugs, such as Interleukin-6 (IL-6) inhibitors, were investigated to determine their effectiveness in the prevention and treatment of COVID-19 infections and complications, including cytokine-storm [6]. Patients with rheumatism are at risk of developing infections due to the disease itself, the drugs they use, and their more serious prognosis during the pandemic. The course of COVID-19 in individuals with rheumatological diseases could not be clearly determined because COVID-19 is a new and recently identified virus, and rheumatic diseases are less common than other diseases. Also, the treatments of rheumatology are very important in COVID-19. The use of cortisone for the treatment of rheumatological diseases causes an increase in overall infection rates, and especially the rate of viral infections, depending on the dose, duration of treatment, and total dosage - but even at dosages considered safe, there is an increased risk of infection. Fredi and colleagues indicate that patients with rheumatic and musculoskeletal diseases do not appear to have a milder form of COVID-19 pneumonia than the controls [7].

Rheumatism patients are at risk of developing infections due to the disease itself, the drugs they use, and their more serious prognosis. The course of COVID-19 in individuals with rheumatological diseases could not be clearly determined because COVID-19 is a new and recently identified virus, and rheumatic diseases are less common than other diseases. In the disease process, scientific methodology and approaches, taking interventions about the disease, were important fighting against the pandemic process. So in this study, we use bibliometric analysis about COVID-19 and rheumatology publications to provide a perspective on studies. In the light of the studies carried out, information can be obtained about the precautions, treatments, and disease processes taken regarding rheumatological patients during COVID-19. The overview and general perspective of the studies can be helpful and useful for the future studies.

So in this study, bibliometric methods were used to analyze publications on rheumatology and COVID-19.
Bibliometric analysis provides a general perspective of the studies about rheumatology and COVID-19.

\section{Materials and methods}

\section{Data sources}

The Web of Science (WoS) Core Collections were used to find publications for analysis. For the analysis, we used the following keywords: "COVID-19" and "Rheumatology"; "Coronavirus" and "Rheumatology"; "2019-nCoV" and "Rheumatology"; "SARS-CoV-2" and "Rheumatology"; "COVID-19" and "Rheumatic Disease"; "Coronavirus" and "Rheumatic Disease"; "2019-nCoV" and "Rheumatic Disease"; "SARS-CoV-2" and "Rheumatic Disease"; "COVID19 " and "Rheumatism"; "Coronavirus" and "Rheumatism"; "2019-nCoV" and "Rheumatism"; and "SARS-CoV-2" and "Rheumatism." The analyzed works (234 in total) were published in 2020 and 2021(February) and include articles and abstracts.

\section{Statistical analysis}

Data received as ANSI files were transferred (version 1.6.16). The bibliometric analysis and all other processes were carried out with VOSviewer. The dataset is an open source. The exported data included annual growth of publications, types of documents, languages, countries, authors, institutions, journals, citations, and funding agencies. The relationships between citation numbers and some related variables were analyzed with Spearman correlation coefficients, and p-values are reported and tested at a significance level of 0.05 using IBM SPSS Statistics 21. VOSviewer was used for visualization which provides better understanding and ease of interpretation of items and its clusters. VOSViewer was also used for constructions of density maps.

\section{Results}

\section{Publication type}

The results show that $46.58 \%$ (109) of the documents were articles and $14.95 \%$ were meeting (seminars etc.) articles. Table 1 shows the document types that were analyzed. The studies were cited 1411 times in total, and 1121 times without self-citations. Most publications, 216 (92.30\%), were written and published in English, followed by 13 (5.55\%) in German, and the remaining five (2.13\%) were in Spanish. 
Table 1 Publication types

\begin{tabular}{lll}
\hline Publication type & Count & $\%$ \\
\hline Article & 109 & 46.58 \\
Meeting abstract & 35 & 14.95 \\
Editorial material & 33 & 14.10 \\
Review & 32 & 13.67 \\
Letter & 21 & 8.97 \\
Early access & 17 & 7.26 \\
News item & 4 & 1.70 \\
\hline
\end{tabular}

Table 2 The top ten list of the number of articles and citations by country

\begin{tabular}{llll}
\hline Country & Documents & Country & Citations \\
\hline USA & 75 & Italy & 672 \\
England & 40 & USA & 454 \\
Italy & 30 & England & 300 \\
Germany & 24 & Canada & 293 \\
Canada & 23 & Spain & 255 \\
Spain & 18 & Australia & 240 \\
Australia & 14 & Germany & 236 \\
Turkey & 12 & France & 207 \\
France & 11 & New Zealand & 205 \\
New Zealand & 9 & Portugal & 190 \\
\hline
\end{tabular}

\section{The number of articles and citations by country}

Table 2 shows the top ten countries ranked by number of articles and citations. The highest number of articles was from the USA, England, Italy, Germany, Canada, Spain, Australia, Turkey, France, and New Zealand. The most cited publications were from Italy, with 672 citations.

\section{Top authors, journals, and organizations}

Table 3 shows the top ten authors ranked by number of documents and citations. For the purpose of analysis, the minimum number of documents per author was set at five. Only ten out of all the authors analyzed contributed to at least five publications. Jinoos Yazdany's articles on rheumatology and COVID-19 were the most cited. Table 3 lists journals ranked by most documents and citations. The minimum number of documents per journal was set at five, and nine journals met this criterion. The Annals of the Rheumatic Diseases was the most cited journal, whereas most articles on rheumatology and COVID-19 were published in Arthritis and Rheumatology. Table 3 lists the organizations that submitted the most articles for publication. The minimum number of documents per organization was set at five. Taking into account the numbers of documents and citations, the ten most active institutions were the University of California San Francisco, The University of Queensland, Harvard Medical School, University of Otago, Canadian Arthritis Patient Alliance, McMaster University, Massachusetts General Hospital, University of Washington, Health Partners, and UCL.

Table 3 The top ten list of the authors, journals, and organizations

\begin{tabular}{|c|c|c|c|c|c|c|c|c|c|}
\hline & Author & Documents & Citations & Journals & Documents & Citations & Organization & Documents & Citations \\
\hline 1 & Jinoos Yazdany & 10 & 113 & $\begin{array}{l}\text { Annals of the Rheu- } \\
\text { matic Diseases }\end{array}$ & 14 & 245 & $\begin{array}{l}\text { University of } \\
\text { California San } \\
\text { Francisco }\end{array}$ & 13 & 234 \\
\hline 2 & Emily Sirotich & 10 & 83 & $\begin{array}{l}\text { Rheumatology Inter- } \\
\text { national }\end{array}$ & 18 & 42 & $\begin{array}{l}\text { The University of } \\
\text { Queensland }\end{array}$ & 12 & 231 \\
\hline 3 & Pedro M. Machado & 7 & 67 & $\begin{array}{l}\text { Clinical Rheumatol- } \\
\text { ogy }\end{array}$ & 16 & 32 & $\begin{array}{l}\text { Harvard Medical } \\
\text { School }\end{array}$ & 12 & 225 \\
\hline 4 & Rebecca Grainger & 7 & 83 & $\begin{array}{l}\text { Lancet Rheumatol- } \\
\text { ogy }\end{array}$ & 11 & 104 & University of Otago & 8 & 205 \\
\hline 5 & Philip Robinson & 5 & 66 & $\begin{array}{l}\text { Seminars in Arthritis } \\
\text { and Rheumatism }\end{array}$ & 5 & 37 & $\begin{array}{l}\text { Canadian Arthritis } \\
\text { Patient Alliance }\end{array}$ & 6 & 201 \\
\hline 6 & Jonathan Hausmann & 5 & 0 & $\begin{array}{l}\text { Arthritis and Rheu- } \\
\text { matology }\end{array}$ & 42 & 83 & $\begin{array}{l}\text { Mc Master Univer- } \\
\text { sity }\end{array}$ & 10 & 201 \\
\hline 7 & Philip C. Robinson & 5 & 47 & $\begin{array}{l}\text { Zeitchrift fur Rheu- } \\
\text { matologie }\end{array}$ & 11 & 11 & $\begin{array}{l}\text { Massachusetts Gen- } \\
\text { eral Hospital }\end{array}$ & 9 & 167 \\
\hline 8 & Roberto Caporali & 6 & 40 & Rheumatology & 6 & 15 & $\begin{array}{l}\text { University of Wash- } \\
\text { ington }\end{array}$ & 8 & 209 \\
\hline 9 & Hamdi Wafa & 5 & 5 & $\begin{array}{l}\text { International Journal } \\
\text { of Rheumatic } \\
\text { Diseases }\end{array}$ & 7 & 4 & HealthPartners & 5 & 193 \\
\hline 10 & Amy S. Mudano & 5 & 63 & & & & $\begin{array}{l}\text { UCL-London's } \\
\text { Global University }\end{array}$ & 12 & 84 \\
\hline
\end{tabular}




\section{International cooperation of countries}

Figure 1 shows the network visualization map of international cooperation among countries that published articles on rheumatology and COVID-19. The size of the circle relates to the number of articles, colors indicate clusters, and line thickness is relative to the strength of the relationship. The minimum number of citations per country was eleven, and twenty countries satisfied this condition.

\section{Network visualization map for citation analysis of active journals}

Figure 2 shows a network visualization map for citations of current journals that publish articles on rheumatology and COVID-19. The size of the circle relates to the number of articles, colors indicate clusters, and line thickness is relative to the strength of the relationship. The minimum number of documents per organization was five, and 26 organizations satisfied this condition.
Fig. 1 Network visualization map for international cooperation of world countries publishing publications on rheumatology and COVID-19
Fig. 2 Network visualization map for citation analysis of active journals on rheumatology and COVID-19
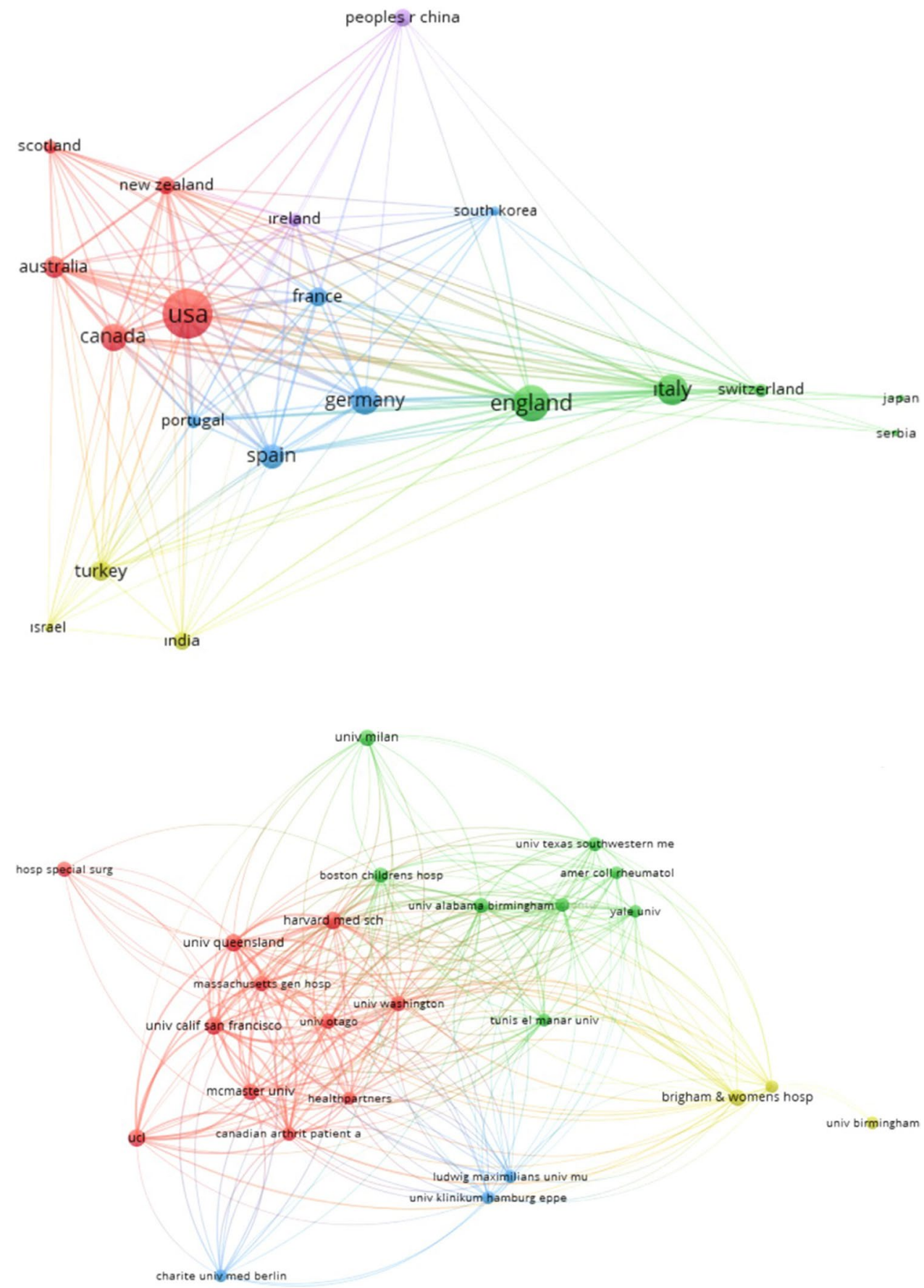
Table 4 The relationship citations numbers between cited references count, 180-day usage count, since 2013 usage count and number of pages

\begin{tabular}{llllll}
\hline & & $\begin{array}{l}\text { Cited refer- } \\
\text { ence count }\end{array}$ & $\begin{array}{l}\text { 180-day } \\
\text { usage count }\end{array}$ & $\begin{array}{l}\text { Since 2013 } \\
\text { usage count }\end{array}$ & Number of pages \\
\hline Times cited, all databases & $\begin{array}{c}\text { Correlation } \\
\text { coefficient }\end{array}$ & 0.344 & 0.274 & 0.449 & 0.182 \\
& $\mathrm{p}$ & $<0.001$ & $<0.001$ & $<0.001$ & 0.005 \\
& $\mathrm{~N}$ & 234 & 234 & 234 & 234 \\
\hline
\end{tabular}

\section{Correlation analysis}

The correlation between the number of citations and the 180-day usage count, the 2013 onward usage count, and the number of pages is shown in Table 4 . The usage count is a measure of the level of interest in a specific item on the WoS platform and reflects the number of times that an article has met a user's information needs. The count is based on the number of clicks to expand the full-length article at the publisher's website or on the number of downloads for use in a bibliographic management tool. The usage count is not a per-institution record-it is a record of all activity by all WoS users. The 180-day usage count is the number of times the full text of a record has been accessed or a record has been saved in the last 6 months. This count can increase or decrease as the timeline advances. The 2013 onward usage count is the number of times the full text of a record has been accessed or a record has been saved since February 1, 2013. This count can increase or remain static over time [8].

There were statistically significant relationships between the number of citations and the variables in the table $(\mathrm{p}<0.001 ; \mathrm{p}=0.005)$. All the relationships were positive, but relationship strengths were low $(r=0.344 ; r=0.274$; $\mathrm{r}=0.449 ; \mathrm{r}=0.182$ ) (Table 4).

\section{Discussion}

Scientific publications are important tools for developing treatments and getting new medical information. Analysis of publication activities helps researchers to have an opinion about the quantity and quality of the research field. Bibliometric analysis can help researchers to make analysis about publication activities with relation to citations, journals, authors etc. It provides information about the structure of investigated field in various categories. Within the aim of the study, a bibliometric analysis was made about rheumatology and COVID-19.

COVID-19 has substantial impact on rheumatology. In rheumatology, scientific methodology and approaches were important fighting against pandemic process and taking control, interventions about the disease. There are many studies about rheumatology and COVID-19. Since the pandemic, researchers worldwide published many papers in a short period. To the best of our knowledge, this paper is the first bibliometric analysis on rheumatology and COVID-19, which could be useful for future studies. This study provides a general perspective of the studies about rheumatology and COVID-19.

The bibliometric analysis summarized 234 publications on rheumatology and COVID-19, which provides an insight into publications and citations by organization, country, and author. Data were taken from the Web of Science (WoS) website. The average number of citations per item was 6.03 . The studies were cited 1411 times in total, and 1121 times without self-citations. Most publications were written and published in English, followed by German and Spanish. There were significant quantity of published papers about COVID-19 and rheumatology. The USA, England, and Italy were the leading countries contributing to the literature about rheumatology and COVID-19 in terms of publication numbers and citations. Since the pandemic emerging in China, Italy becoming one of the countries dealing with the COVID-19. So the majority of papers were published by Italy. China was the most affected by the initial outbreak of the pandemic; on the top list of publications and citations from China was not present. The Annals of the Rheumatic Diseases was the most productive journal; University of California San Francisco was the most productive institution in terms of rheumatology and COVID-19 research.

The limitation of the study was that databases such PubMed, Scopus, and Google Scholar are not included in our study.

\section{Conclusion}

Bibliometric analysis of rheumatology and COVID-19 can be useful to future studies because it provides a general perspective on the studies. Bibliometric analysis about rheumatology and COVID-19 can be useful and helpful tool for future studies. This study provides an insight into the development of publications on rheumatology during the COVID-19 pandemic.

Author contribution Concept-O.P., T.P.; design-O.P., T.P.; supervision-O.P., T.P.; resources-O.P., T.P.; materials-O.P., T.P.; data 
collection and/or processing-O.P.; analysis and/or interpretationO.P.; literature review-O.P., T.P.; writing-O.P., T.P.; critical review-O.P., T.P.

\section{Data availability N/A}

\section{Declarations}

\section{Ethics approval N/A}

Disclosures None.

\section{References}

1. Zhou P, Yang X-L, Wang X-G et al (2020) A pneumonia outbreak associated with a new coronavirus of probable bat origin. Nature 579:270-273

2. Wu Z, McGoogan JM (2020) Characteristics of and important lessons from the coronavirus disease 2019 (COVID-19) outbreak in China: summary of a report of 72314 cases from the Chinese Center for Disease Control and Prevention. JAMA 323(13):1230 1242. https://doi.org/10.1001/jama.2020.2648
3. Yang X, Yu Y, Xu J et al (2020) Clinical course and outcomes of critically ill patients with SARS-CoV-2 pneumonia in Wuhan, China: a single-centered, retrospective, observational study. Lancet Respir Medicine 8(5):475-481

4. Sepriano A, Kerschbaumer A, Josef SS et al (2020) Safety of synthetic and biological DMARDs: a systematic literature review informing the 2019 update of the EULAR recommendations for the management of rheumatoid arthritis. Ann Rheum Dis 79(6):760-770

5. Siemieniuk RAC, Jessica Bartoszko J, Long Ge et al (2020) Drug treatments for COVID-19: living systematic review and network meta-analysis. BMJ 370:m2980

6. Mehta P, McAuley DF, Brown M et al (2020) COVID-19: consider cytokine storm syndromes and immunosuppression. Lancet 395:1033-1034

7. Fredi M, Cavazzana I, Moschetti L et al (2020) COVID-19 in patients with rheumatic diseases in northern Italy: a single-centre observational and case-control study. The Lancet Rheumatology 2(9):e549-e556

8. Clarivate Analytics (2020) Web of Science Core Collection Help Usage Count https://images.webofknowledge.com/images/help/ WOS/hp_usage_score.html. Accessed 15 Feb 2020

Publisher's note Springer Nature remains neutral with regard to jurisdictional claims in published maps and institutional affiliations. 